Full Length Article

\title{
Supramolecular architectures of iron phthalocyanine Langmuir-Blodgett films: The role played by the solution solvents
}

\author{
Rafael Jesus Gonçalves Rubira ${ }^{\mathrm{a}}$, Pedro Henrique Benites Aoki ${ }^{\mathrm{b}}$, \\ Carlos José Leopoldo Constantino ${ }^{a}$, Priscila Alessio ${ }^{\mathrm{a}, *}$ \\ a São Paulo State University (UNESP), School of Technology and Applied Sciences, Presidente Prudente, SP, Brazil \\ b São Paulo State University (UNESP), School of Sciences, Humanities and Languages, Assis, SP, Brazil
}

\section{A R T I C L E I N F O}

\section{Article history:}

Received 23 February 2017

Received in revised form 10 April 2017

Accepted 19 April 2017

Available online 23 April 2017

\section{Keywords:}

Langmuir

Langmuir-Blodgett

Supramolecular architecture

Pollutant

Atrazine

\begin{abstract}
A B S T R A C T
The developing of organic-based devices has been widely explored using ultrathin films as the transducer element, whose supramolecular architecture plays a central role in the device performance. Here, Langmuir and Langmuir-Blodgett (LB) ultrathin films were fabricated from iron phthalocyanine (FePc) solutions in chloroform $\left(\mathrm{CHCl}_{3}\right)$, dichloromethane $\left(\mathrm{CH}_{2} \mathrm{Cl}_{2}\right)$, dimethylformamide (DMF), and tetrahydrofuran (THF) to determine the influence of different solvents on the supramolecular architecture of the ultrathin films. The UV-vis absorption spectroscopy shows a strong dependence of the FePc aggregation on these solvents. As a consequence, the surface pressure vs. mean molecular area $(\pi-A)$ isotherms and Brewster angle microscopy (BAM) reveal a more homogeneous (surface morphology) Langmuir film at the air/water interface for FePc in DMF. The same morphological pattern observed for the Langmuir films is preserved upon LB deposition onto solid substrates. The Raman and FTIR analyses indicate the DMF$\mathrm{FePc}$ interaction relies on coordination bonds between $\mathrm{N}$ atom (from DMF) and Fe atom (from FePc). Besides, the FePc molecular organization was also found to be affected by the DMF-FePc chemical interaction. It is interesting to note that, if the DMF-FePc leads to less aggregated FePc either in solution or ultrathin films (Langmuir and LB), with time (one week) the opposite trend is found. Taking into account the N-Fe interaction, the performance of the FePc ultrathin films with distinct supramolecular architectures composing sensing units was explored as proof-of-principle in the detection of trace amounts of atrazine herbicide in water using impedance spectroscopy. Further statistical and computational analysis reveal not only the role played by FePc supramolecular architecture but also the sensitivity of the system to detect atrazine solutions down to $10^{-10} \mathrm{~mol} / \mathrm{L}$, which is sufficient to monitor the quality of drinking water even according to the most stringent international regulations.
\end{abstract}

(C) 2017 Elsevier B.V. All rights reserved.

\section{Introduction}

The design of supramolecular structures has been at the forefront of technological applications [1-5] paving the way for developing nanoarchitectonics [6]. Different strategies can be employed to produce such structures, but the emphasis has been given to techniques that allow controlling molecular architectures, including Layer-by-Layer [7] physical evaporation, [8] Langmuir and Langmuir-Blodgett films [9-12]. In these cases, different supramolecular architectures can be achieved by tuning experimental conditions, such as i) deposition methods [1] ii) thermal annealing [13] iii) solvent interaction [14,15] among

\footnotetext{
* Corresponding author.

E-mail address: priscila@fct.unesp.br (P. Alessio).
}

others. For instance, Xiao et al. [16] have shown the influence of different solvents on the morphology and crystallinity of poly(3-hexylthiophene) (P3HT) thin films. The importance of the o-xylenesolvent to improve the Langmuir-Schaeffer (LS) deposition of copper tetra-(tertbutyl)-phthalocyanine was presented by Kolker et al. [17-19]. Chiang et al. [14] have found the methyl sulfoxide solvent interferes with the PEDOT conformation, affecting the electrochemical properties of the films. PEDOT with linear conformation displays higher conductivity and reversibility for ion exchange, which increases the sensitivity of electrochromic devices [14].

Phthalocyanines (Pc) attract great attention due to their thermal and chemical stability, electrical and optical properties, and the possibility of thin film fabrication [20-24]. However, the strong $\pi-\pi$ stacking interactions significantly reduce the solubility of metal Pc in organic solvents [25-28]. In this work, Langmuir and 
Langmuir-Blodgett (LB) films were fabricated from FePc solutions in chloroform $\left(\mathrm{CHCl}_{3}\right)$, dichloromethane $\left(\mathrm{CH}_{2} \mathrm{Cl}_{2}\right)$, dimethylformamide (DMF), and tetrahydrofuran (THF) to investigate the influence of these different solvents on both optical absorption and morphological properties of the films. The solvents were chosen according to their polarity (Fig. S1) and presence (or not) of $\mathrm{N}$ e $\mathrm{O}$ atoms in their molecular structure. The FePc was chosen mainly due to the metal core (Fe), susceptible to coordination with nitrogenous and phenolic groups [29-31]. As proof-of-principle, FePc LB films with distinct supramolecular architectures were evaluated as sensing units in the detection of trace amounts of atrazine herbicide in water through impedance spectroscopy. The impedance data were further analyzed using multidimensional projection techniques and principal component analysis (PCA) to demonstrate the effect of the different LB supramolecular architectures on the sensing unit distinction ability. Atrazine belongs to the s-triazine family, being widely used in combating weeds in many different crops [32], which can potentially lead to contamination of the environment, especially the groundwater. Depending on the concentration, it can act as an inhibitor of photosynthesis [33,34] and may present endocrine disruptor or carcinogenic effects [35-37].

\section{Materials and methods}

\subsection{Reagents and solutions}

Iron phthalocyanine $(\mathrm{FePc}, \mathrm{MW}=568.38 \mathrm{~g} / \mathrm{mol}$ ) was purchased from Kodak and used as received. FePc solutions were prepared at $0.5 \mathrm{mg} / \mathrm{mL}\left(8.8 \times 10^{-4} \mathrm{~mol} / \mathrm{L}\right)$ using chloroform $\left(\mathrm{CHCl}_{3}\right)$, dichloromethane $\left(\mathrm{CH}_{2} \mathrm{Cl}_{2}\right)$, tetrahydrofuran (THF), and dimethylformamide (DMF), whose molecular structures are given in Fig. $\mathrm{S} 1$. The atrazine pesticide $\left(\mathrm{C}_{8} \mathrm{H}_{14} \mathrm{ClN}_{5}, \mathrm{MM}=215.68 \mathrm{~g} / \mathrm{mol}\right.$, Fig. S1 $)$, purity $=98.8 \%$, was purchased from Fluka Analytical-Brazil. The solutions were prepared by simply adding FePc powder to the reagents followed by $30 \mathrm{~min}$ of sonication. All solvents are HPLC grade acquired from Merck. The ultrapure water $(18.2 \mathrm{M} \Omega \mathrm{cm})$ was acquired from a Milli-Q system, model Simplicity.

\subsection{Langmuir and Langmuir-Blodgett (LB) films}

The FePc Langmuir and Langmuir-Blodgett (LB) films were fabricated using a KSV Langmuir trough, model 2000. Langmuir films were prepared by spreading $350 \mu \mathrm{L}$ of FePc solutions $\left(8.8 \times 10^{-4} \mathrm{~mol} / \mathrm{L}\right)$ onto the water subphase $(1.3 \mathrm{~L})$. The solvent was allowed to evaporate for ca. 20 min before the first compression. The Langmuir monolayers were characterized by surface pressure vs. mean molecular area $(\pi-A)$ isotherms at $23^{\circ} \mathrm{C}$ using the Wilhelmy method. The monolayer was symmetrically compressed under a constant barrier speed of $10 \mathrm{~mm} / \mathrm{min}$. Brewster angle microscopy (KSV, model micro-BAM) images were also acquired for different areas during the Langmuir film compression.

The LB films were obtained by transferring the FePc Langmuir monolayers from the air/water interface to different solid substrates depending on the characterization technique to be applied. The surface pressure was kept constant at $25 \mathrm{mN} / \mathrm{m}$ during ca. 15 min prior the LB deposition, controlled by the displacement of the barriers ( $1 \mathrm{~mm}$ of displacement every $5 \mathrm{~min}$ ). Y-type LB films were obtained by using an upstroke and downstroke speed of ca. $2.0 \mathrm{~mm} / \mathrm{min}$. FePc LB films containing up to 21 layers were deposited onto quartz substrate for ultraviolet-visible (UV-vis) absorption spectroscopy and onto ZnSe for FTIR measurements. FePc LB films containing five layers were deposited onto Pt interdigitated electrodes (IDE, 50 pairs of digits with $10 \mu \mathrm{m}$ width, $0.5 \mathrm{~mm}$ length and $100 \mathrm{~nm}$ height, and $10 \mu \mathrm{m}$ apart each other) for impedance spectroscopy.

\subsection{Characterization techniques}

The UV-vis absorption spectra were recorded for FePc solutions and LB films using a Varian spectrophotometer, model Cary 50, from 190 to $1100 \mathrm{~nm}$. The micro-Raman scattering experiments were conducted with a micro-Raman Renishaw spectrograph, model inVia, with laser excitation at $633 \mathrm{~nm}$. The system is equipped with a Leica microscope, whose 50x (NA 0.75) objective lens allows collecting spectra with ca. $1 \mu \mathrm{m}^{2}$ spatial resolution. Single-point spectra were recorded with ca. $4 \mathrm{~cm}^{-1}$ resolution and $10 \mathrm{~s}$ accumulation time using a computer-controlled motorized stage $(\mathrm{XY})$. The FTIR spectra were taken on a Bruker spectrometer, model Tensor 27, between 4000 and $500 \mathrm{~cm}^{-1}$. FTIR measurements were performed using the transmission mode with 128 scans and spectral resolution of $4 \mathrm{~cm}^{-1}$. The surface morphology was characterized through AFM using a Nanosurf Instrument, model easyScan 2, with a tip of silicon nitride and using the tapping mode. All topographic images were collected with a resolution of 512 lines per scan at a scan rate of $0.5 \mathrm{~Hz}$. The images were processed with the software Gwyddion 2.19 .

Impedance spectroscopy measurements were performed using a Solartron analyzer model $1260 \mathrm{~A}$. Impedance spectra were acquired from $1 \mathrm{~Hz}$ to $1 \mathrm{MHz}$ using $50 \mathrm{mV}$ of amplitude. The sensing array is composed of four sensing units: a bare Pt interdigitated electrode (IDE) and three Pt IDEs coated with 5 LB layers built up from FePc solutions in $\mathrm{CH}_{2} \mathrm{Cl}_{2}$, DMF/freshly prepared and DMF/aged for one week, as illustrated in Fig. S2. The bare Pt electrode was used to monitor any change in the electrical response caused by the ultrathin films. The measurements were performed with sensing units immersed into ultrapure water $(18.2 \mathrm{M} \Omega \mathrm{cm})$ used as a reference and into atrazine aqueous solutions at $0.1 \times 10^{-9}, 1.0 \times 10^{-9}$, $15 \times 10^{-9}, 50 \times 10^{-9}$, and $100 \times 10^{-9} \mathrm{~mol} / \mathrm{L}$. The course of measurements started from the lowest $\left(0.1 \times 10^{-9} \mathrm{~mol} / \mathrm{L}\right)$ to the highest $\left(100 \times 10^{-9} \mathrm{~mol} / \mathrm{L}\right)$ atrazine concentrations. Between each set of measurements involving a specific concentration of atrazine, the sensing units were carefully washed with ultrapure water. The sensing units were left soaking $20 \mathrm{~min}$ inside the solutions before data acquisition to enable a stable reading. The impedance data were further analyzed using multidimensional projection techniques, whose details can be found in Oliveira et al. [38] and Paulovich et al. [39].

\section{Results and discussion}

\subsection{FePc Langmuir films}

\subsection{1. $\pi$-A isotherms}

Fig. 1 shows the $\pi$-A isotherms for FePc in $\mathrm{CHCl}_{3}, \mathrm{CH}_{2} \mathrm{Cl}_{2}, \mathrm{THF}$, and DMF. Similar profiles are found for both $\mathrm{FePc} / \mathrm{CH}_{2} \mathrm{Cl}_{2}$ and $\mathrm{FePc} / \mathrm{CHCl}_{3} \pi$-A isotherms, considering all the compression stages. The corresponding liquid-phase (up to $15 \mathrm{mN} / \mathrm{m}$ ) of the FePc/THF is displaced towards larger molecular areas, which suggests an interaction between FePc and THF, unperceived for $\mathrm{CHCl}_{3}$ and $\mathrm{CH}_{2} \mathrm{Cl}_{2}$ solvents. There is a possibility of a coordination of the DMF oxygen with the FePc iron, leading to the formation of dimeric species of FePc, as reported by Barbosa et al. [30] working with $\mathrm{Mg}-\mathrm{Al}$ hydrotalcite-like materials used as support for the immobilization of $\mathrm{Fe}$ (III) tetrasulfonated phthalocyanine (FePcTs). However, at higher surface pressures (above $15 \mathrm{mN} / \mathrm{m}$ ) the FePc/THF $\pi$-A isotherm tends to overlap the $\mathrm{FePc} / \mathrm{CH}_{2} \mathrm{Cl}_{2}$ and $\mathrm{FePc} / \mathrm{CHCl}_{3} \pi-\mathrm{A}$ isotherms. The later indicates the FePc-THF interaction is not strong enough, and the final packaging of FePc molecules is substantially the same as in $\mathrm{CHCl}_{3}$ and $\mathrm{CH}_{2} \mathrm{Cl}_{2}$. Therefore, the formation of FePc dimeric species through coordination interaction can be minimized. Besides, the FePc solutions in $\mathrm{CHCl}_{3}, \mathrm{CH}_{2} \mathrm{Cl}_{2}$, and THF have 


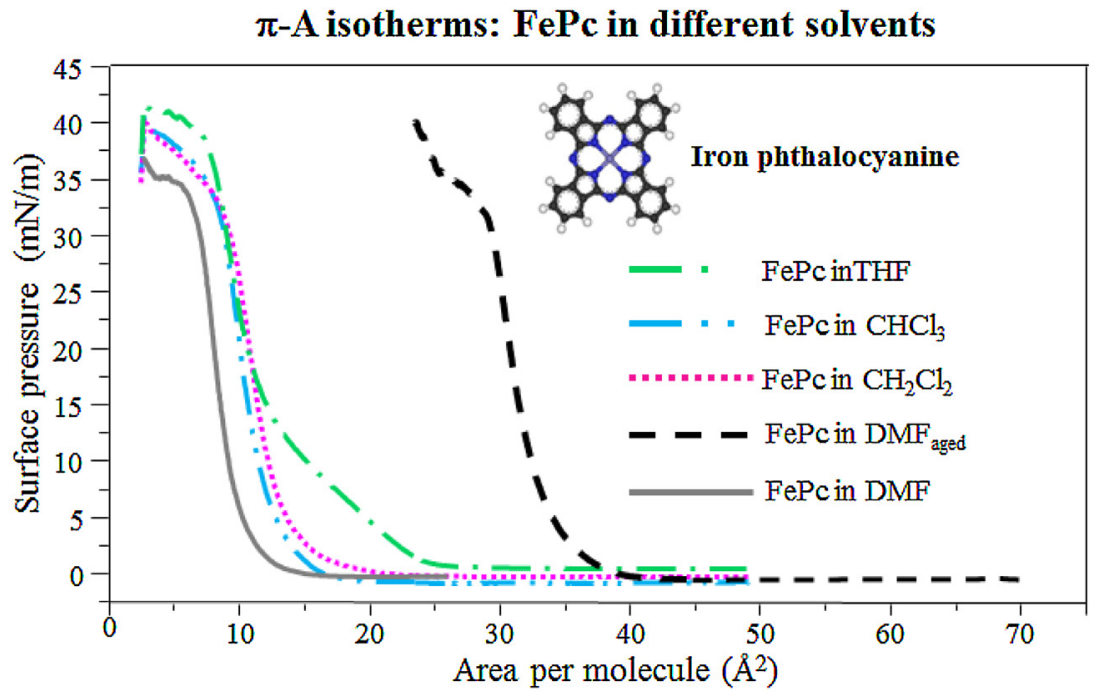

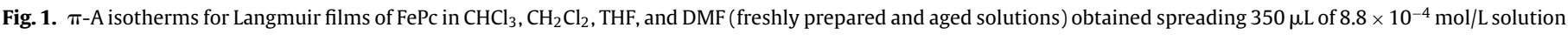
onto ultrapure water subphase at $23^{\circ} \mathrm{C}$.

proven to be stable with time, providing reproducible Langmuir films even after months of the prepared solution.

On the other hand, considering the DMF solvent, the displacement of the FePc/DMF isotherm to smaller molecular areas is evidence of a packed monolayer. However, the FePc/DMF $\pi-\mathrm{A}$ isotherm was significantly displaced to larger molecular areas after one week of the solution preparation. The later indicates a timedependent interaction between FePc and DMF, which is going to be discussed in detail in further sections.

\subsubsection{Morphology (BAM)}

Fig. 2a shows BAM images recorded for $\mathrm{FePc} / \mathrm{CH}_{2} \mathrm{Cl}_{2}$ Langmuir film at $20 \mathrm{mN} / \mathrm{m}$. The results obtained for FePc/DMF freshly prepared and after one week of the solution preparation $\left(\mathrm{FePc} / \mathrm{DMF}_{\mathrm{aged}}\right)$ are given in Fig. $2 \mathrm{~b}$. As the time goes on, the $\mathrm{FePc} / \mathrm{DMF}$ film becomes rougher, with the coalescence of molecular domains. Nevertheless, the surface morphology for FePc/DMF and $\mathrm{FePc} / \mathrm{DMF}_{\text {aged }}$ is still more homogeneous than that for $\mathrm{FePc} / \mathrm{CH}_{2} \mathrm{Cl}_{2}$ Langmuir films. These effects might be explained taking into account the interaction established while in the solutions between FePc and solvents, as we shall demonstrate with UV-vis absorption spectroscopy.

\subsubsection{Solution UV-vis absorption}

Fig. 3a shows UV-vis absorption spectra of $\mathrm{FePc}$ in $\mathrm{CHCl}_{3}$, $\mathrm{CH}_{2} \mathrm{Cl}_{2}$, THF, and DMF $8.8 \times 10^{-4} \mathrm{~mol} / \mathrm{L}$ solutions (freshly prepared). In general, the phthalocyanine spectra display a Soret band (or B-band) between 300 and $400 \mathrm{~nm}$ and a Q-band between 550 and $800 \mathrm{~nm}$, which are assigned to $\pi \rightarrow \pi^{*}$ transition between bonding and antibonding molecular orbitals [40]. The Q-band usually displays two maxima of absorption at lower (blue-shift) and higher (red-shift) wavelengths. It is well established the blue-shift is due to the absorption of dimers (and higher orders of molecular aggregates [41]) and the red-shift is due to the absorption of monomeric species of phthalocyanine molecules $[25,28,40]$. In our case, more than two maxima are frequently seen for FePc (Fig. 3a), whose difference in energy among these maxima (within tenths of $\mathrm{eV}$ ) suggests transitions from the fundamental to different vibrational levels of the electronic excited state [40].

Similar spectra were recorded for FePc solutions in $\mathrm{CHCl}_{3}$, $\mathrm{CH}_{2} \mathrm{Cl}_{2}$, and THF, suggesting the FePc molecules are found with similar aggregation level in these media. The broad Q-band observed for FePc in these solvents is similar to the spectrum profile found for FePc in the solid state, whose absorption is assigned to exciton coupling between adjacent macrocycles [40]. Indeed, the FePc spectra from $8.8 \times 10^{-4} \mathrm{~mol} / \mathrm{L} \mathrm{CH}_{2} \mathrm{Cl}_{2}$ solution (Fig. 3a) and LB film (Fig. 4d) are pretty similar (broader). However, in the case of DMF, the $8.8 \times 10^{-4} \mathrm{~mol} / \mathrm{L}$ solution spectrum (sharper - Fig. $3 \mathrm{a}$ ) is quite different from the LB film spectrum (broader - Fig. 4d). In this sense, Fig. S3a shows UV-vis absorption spectra for FePc in $\mathrm{CH}_{2} \mathrm{Cl}_{2}$ diluted solutions $\left(8.8 \times 10^{-5}-5.5 \times 10^{-6} \mathrm{~mol} / \mathrm{L}\right)$, whose sharp profiles are similar to $8.8 \times 10^{-4} \mathrm{~mol} / \mathrm{L}$ DMF solution, revealing the potential of DMF to dissolve FePc even at high concentrations, leading to less aggregation. Regarding the maximum of the absorption bands, they are shifted from $796 \mathrm{~nm}$ for $\mathrm{FePc} / \mathrm{THF}$ to $773 \mathrm{~nm}$ for $\mathrm{FePc} / \mathrm{CHCl}_{3}$ and $768 \mathrm{~nm}$ for $\mathrm{FePc} / \mathrm{CH}_{2} \mathrm{Cl}_{2}$ (Fig. 3b), which must be related to different levels of FePc aggregation. The UV-vis absorption spectrum for FePc in $\mathrm{CH}_{2} \mathrm{Cl}_{2}$ was not affected over time, as shown in Fig. S3b.

The profile of the FePc UV-vis absorption spectrum is significantly affected when in DMF solution (Fig. 3a), with maximum absorption at $662 \mathrm{~nm}$ assigned to dimers (and higher orders of molecular aggregates [41]), $682 \mathrm{~nm}$ assigned to monomers $[25,28,40]$, and a broad band at $771 \mathrm{~nm}$. This profile change suggests the FePc-DMF interaction is distinct that observed for $\mathrm{CHCl}_{3}$, $\mathrm{CH}_{2} \mathrm{Cl}_{2}$, and THF, consistent with the $\pi$-A isotherms for Langmuir films. The $\pi$-A isotherms also revealed the FePc-DMF interaction is time-dependent, which can be correlated with significant variations in the relative intensities of the UV-vis absorption spectrum observed after one week, as shown in Fig. 3b and Fig. S3c. The maximum at $662 \mathrm{~nm}$ (dimers and higher orders of molecular aggregates) increases with time while the maximum at $682 \mathrm{~nm}$ (monomers) and the broad band at $771 \mathrm{~nm}$ decrease. The latter $(771 \mathrm{~nm})$ could also be assigned to monomers due to its opposite trend comparing to the maximum at $662 \mathrm{~nm}$. These spectral changes are clearly assigned to aggregation of FePc molecules over time, i.e., if the DMF leads to less aggregated FePc in fresh solution, with time (one week) the opposite trend is found. However, this increase in aggregation is not as much as for the other solvents. For instance, the sharp UV-vis spectrum of FePc/DMF aged solution (Fig. 3b) is far from the broad spectrum for FePc in the other solvents (Fig. 3a). Leznoff and Lever [40] have reported the coordination established between FePc and DMSO (dimethyl sulfoxide) or DMA (dimethylacetamide) solvents. Interactions between amine groups and iron have already been reported for layer-by-layer (LbL) films of FePc and poly(allylamine hydrochloride) [29,42]. Therefore, it is likely the $\mathrm{N}$ atom of DMF establishes an interaction with the Fe atom of 


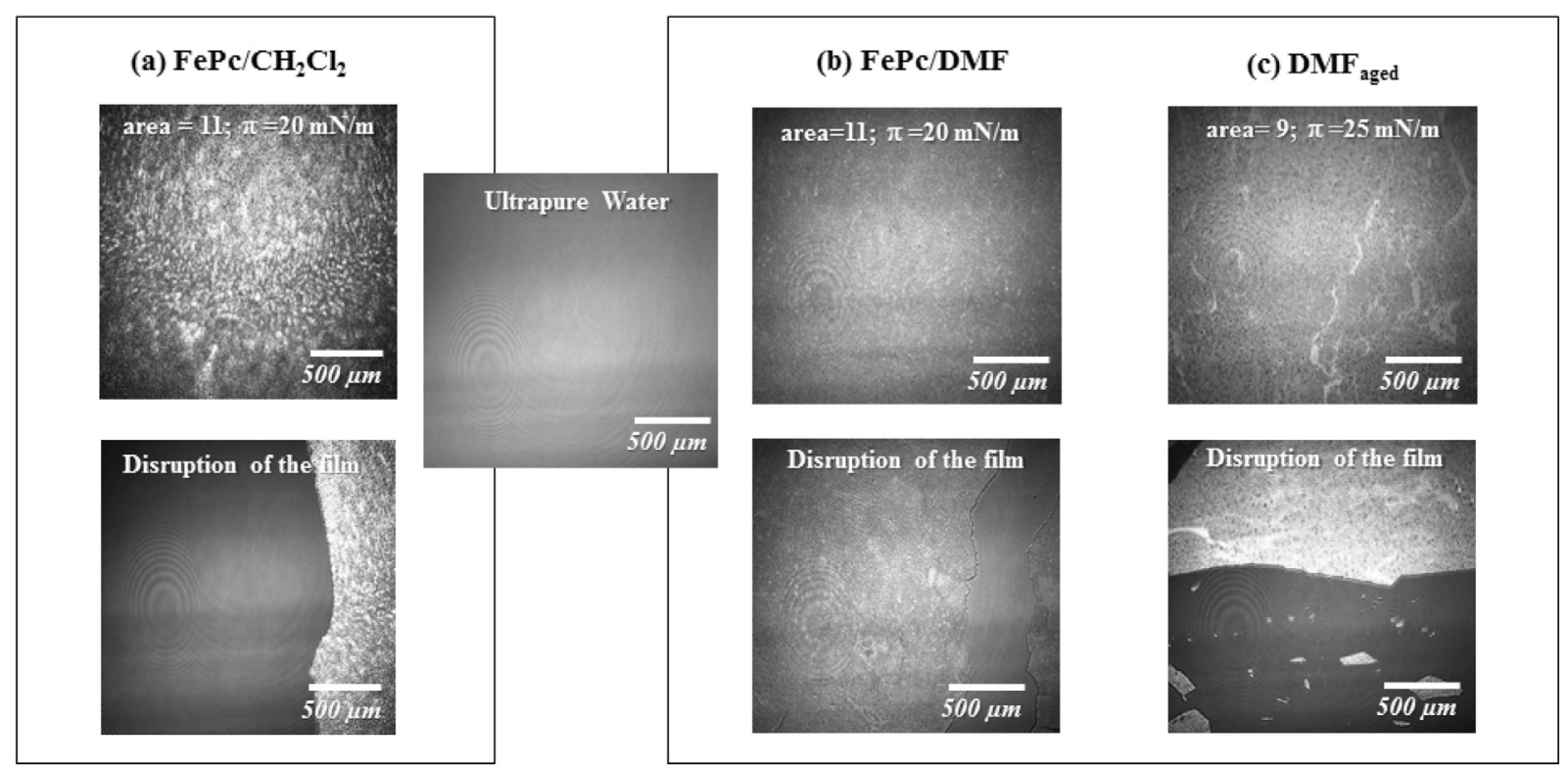

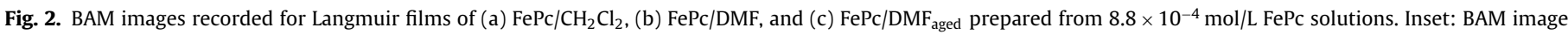
recorded for ultrapure water subphase used as a reference.

(a) UV-Vis: FePc in different solvents

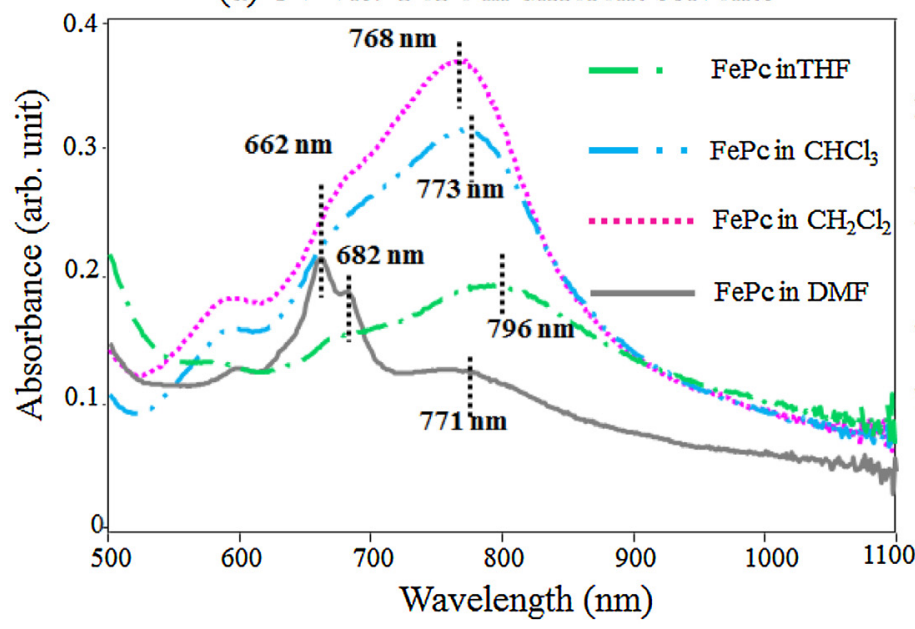

(b) UV-Vis: FePc in DMF solvent

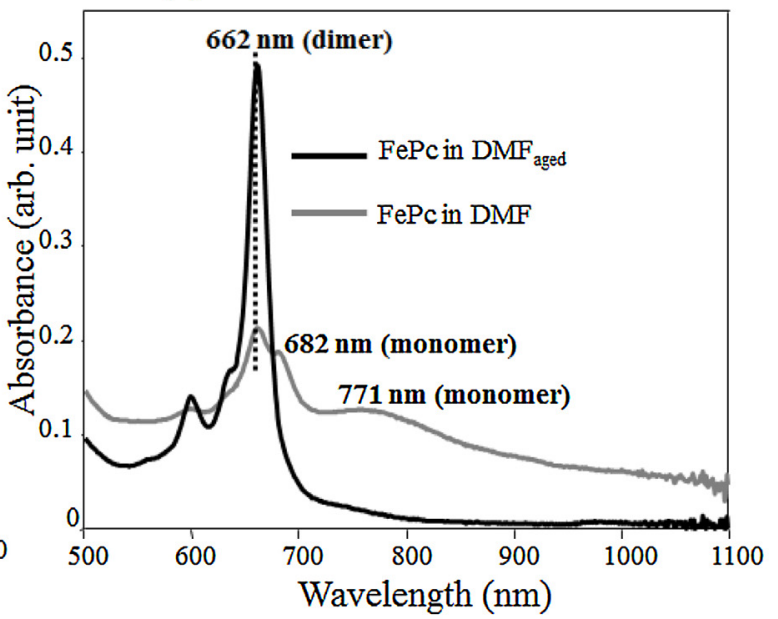

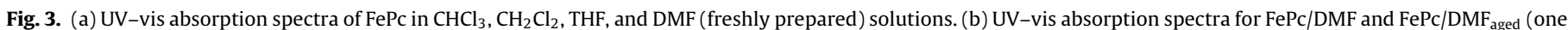
week) solutions. Concentration of all solutions: $8.8 \times 10^{-4} \mathrm{~mol} / \mathrm{L}$.

FePc, which is time dependent. Therefore, the FePc-solvent interaction established while in solution might be incorporated into the Langmuir films, affecting their supramolecular structure at the air/water interface.

\subsection{Langmuir-Blodgett (LB) films}

\subsubsection{Optical property and growth}

LB films of $\mathrm{FePc} / \mathrm{CH}_{2} \mathrm{Cl}_{2}$, FePc/DMF, and FePc/DMF $\mathrm{Dged}_{\text {aged for }}$ one week) were grown at a constant surface pressure of $25 \mathrm{mN} / \mathrm{m}$. At this value, the FePc Langmuir films are already well packed onto the water subphase, regardless the solvent used. The optical absorption and the growth of the LB films were monitored using UV-vis absorption spectroscopy. The spectra were recorded every two layers up to 21 layers (Fig. S4), and the maximum of absorbance for each deposited layer is shown in Fig. 4a-c. Despite the presence of molecular aggregates, it is interesting to note the linear growth of the absorbance with the number of LB layers (in aver- age), which indicates a controlled growth of the LB films. Fig. 4d shows the UV-vis absorption spectra for 21-layer LB films from $\mathrm{CH}_{2} \mathrm{Cl}_{2}$, DMF, and $\mathrm{DMF}_{\text {aged }}$, which are out of scale in absorbance to stress the direct relationship between the molecular aggregates and the UV-vis band shape. The FePc/DMF aged band shape seems to be an intermediate stage between FePc/DMF and $\mathrm{FePc} / \mathrm{CH}_{2} \mathrm{Cl}_{2}$, as a consequence of the FePc aggregation when growing LB films from these solvents.

\subsubsection{Morphology at micrometer scale (micro-Raman)}

Fig. 5 shows the micro-Raman images collected for LB films containing 21 layers of $\mathrm{FePc} / \mathrm{CH}_{2} \mathrm{Cl}_{2}, \mathrm{FePc} / \mathrm{DMF}$, and FePc/DMF Optical images show the morphology of the LB films agrees with the BAM images recorded for the Langmuir films, i.e., larger FePc molecular domains (aggregates) for $\mathrm{FePc} / \mathrm{CH}_{2} \mathrm{Cl}_{2}$ film and, consequently, higher homogeneity (surface morphology) for FePc/DMF LB films. The characterization of such aggregates was performed by Raman spectroscopy collecting spectra point-by-point along a line 
(a) UV-Vis: LB film of $\mathrm{FePc} / \mathrm{CH}_{2} \mathrm{Cl}_{2}$

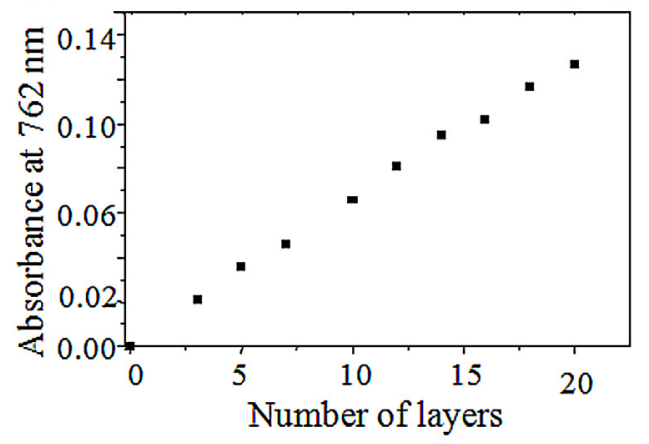

(c) UV-Vis: LB film of FePc/DMF ${ }_{\text {aged }}$

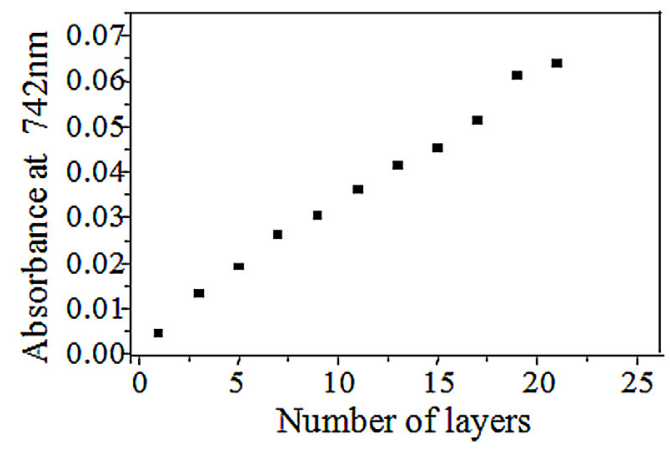

(b) UV-Vis: LB film of FePc/DMF

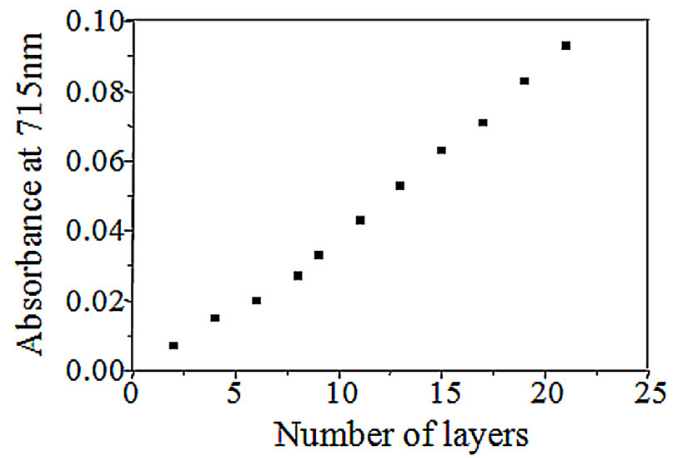

(d) 21-layer FePc LB film

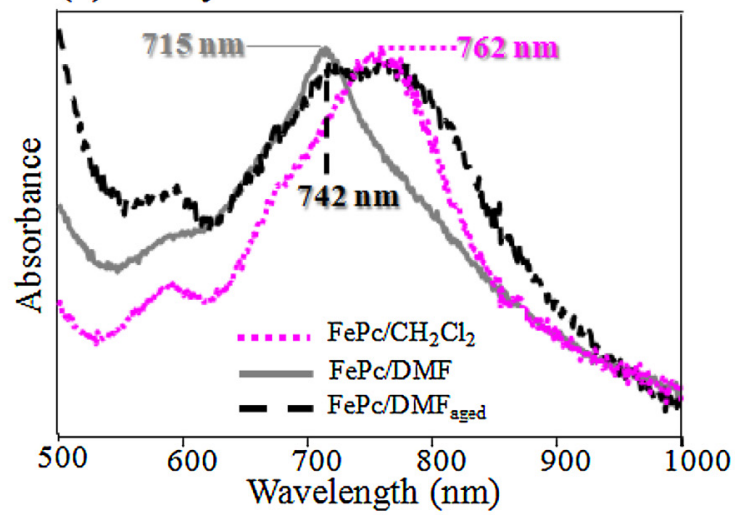

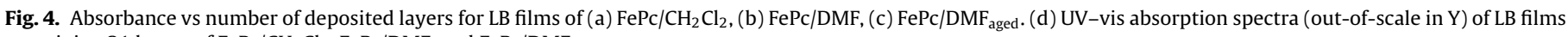
containing 21 layers of $\mathrm{FePc} / \mathrm{CH}_{2} \mathrm{Cl}_{2}, \mathrm{FePc} / \mathrm{DMF}$, and $\mathrm{FePc} / \mathrm{DMF}_{\text {aged }}$.

of $100 \mu \mathrm{m}$ with a $1 \mu \mathrm{m}$ step. The results are shown in Fig. 5, where the 101 spectra collected point-by-point are exhibited in 2 and 3dimensions. The line mapping exhibited in 2-dimensions shows the intensity of the band at $1517 \mathrm{~cm}^{-1}$ assigned to CNC stretching and $\mathrm{C}-\mathrm{H}$ deformation [42-44], where the brighter spots are related to more intense Raman signals. The same analysis is made for the Raman mapping exhibited in 3-dimensions, where the strong variation of the whole Raman spectrum is observed along the mapped line. The Raman mappings (chemical information) are compatible with optical images (morphological information). Regions with aggregates present stronger Raman signal, confirming the FePc in the aggregate composition, which is in agreement with what was previously observed by Alessio et al. [42] working with layer-bylayer (LbL) films of FePc/poly(allylamine hydrochloride) (PAH). The authors found the FePc molecular aggregates play a central role, allowing the LbL film growth through $\mathrm{NH}_{2}$ (from $\mathrm{PAH}$ ) and $\mathrm{Fe}$ (from $\mathrm{FePc}$ ) interactions.

\subsubsection{Morphology at the nanometer scale (AFM)}

AFM measurements for 21 layers of $\mathrm{FePc} / \mathrm{CH}_{2} \mathrm{Cl}_{2}, \mathrm{FePc} / \mathrm{DMF}$, and FePc/DMF $F_{\text {aged }}$ LB films were carried out to evaluate the solvent effect on the morphology of the LB films at the nanometric scale, as shown in Fig. 6. Also, AFM results were analyzed through RMS roughness, given by the standard deviation following the equation $R_{r m s}=\sqrt{\frac{\sum_{n=1}^{n}\left(z_{n}-\bar{Z}\right)^{2}}{N-1}}$, where $\bar{Z}$ is the mean of the $Z$ values within the given area, $Z_{n}$ is the height of the nth pixel, and $N$ is the number of pixels considered within the given area. The measurements were taken from areas of $10 \mu \mathrm{m} \times 10 \mu \mathrm{m}$ and the RMS roughness for FePc/DMF and FePc/DMF ${ }_{\text {aged }}$ LB films was found to be ca. 2.3 and $5.3 \mathrm{~nm}$, respectively. The RMS roughness has significantly increased to ca. $23.3 \mathrm{~nm}$ considering the $\mathrm{FePc} / \mathrm{CH}_{2} \mathrm{Cl}_{2} \mathrm{LB}$ film. The latter indicates the FePc/DMF and FePc/DMF aged $_{\text {LB films }}$ present higher homogeneity (surface morphology) at nanometric scale when compared to $\mathrm{FePc} / \mathrm{CH}_{2} \mathrm{Cl}_{2}$, in agreement to what was previously observed at micrometric level via BAM (Langmuir films) and micro-Raman (LB films).

\subsubsection{FePc-solvent chemical interaction (vibrational spectroscopy)}

Fig. 7 shows the Raman spectra of FePc/DMF and FePc/DMF aged collected for both aggregates and smooth regions of the LB films. A similar profile is observed for the spectra collected from the aggregates (fresh and aged). Small differences arise because the FePc molecular aggregates are less susceptible to the solvent action. Comparing the spectra of the smooth region, the bands at 680 and $749 \mathrm{~cm}^{-1}$ (macrocycle vibration, $\mathrm{C}-\mathrm{N}-\mathrm{C} \mathrm{N}-$ Fe stretching, benzene and $\mathrm{C}-\mathrm{H}$ deformation $[42,44])$ showed a small decrease in relative intensity, and the bands between 1400 and $1540 \mathrm{~cm}^{-1}$ were shifted. The bands at $1307 \mathrm{~cm}^{-1}(\mathrm{C}-\mathrm{H}$ in-plane bending, isoindole stretching $\mathrm{N}-\mathrm{Fe})$ and $1401 \mathrm{~cm}^{-1}(\mathrm{C}-\mathrm{N}-\mathrm{C}$ stretching, pyrrole expansion and $\mathrm{C}-\mathrm{H}$ in-plane bending) [42-44] were significantly affected (decrease in relative intensity and a shift in wavenumber) for FePc/DMF aged LB film. These spectral changes confirm the coordination bonds between $\mathrm{N}-\mathrm{Fe}$, as initially discussed for $\pi$-A isotherms and UV-vis absorption. The $\mathrm{FePc} / \mathrm{CH}_{2} \mathrm{Cl}_{2}$ Raman spectra taken from both aggregates and smooth regions presented profiles similar to the FePc/DMF Raman spectra collected from aggregates (Fig. S5). 
LB film of $\mathrm{FePc} / \mathrm{CH}_{2} \mathrm{Cl}_{2}$
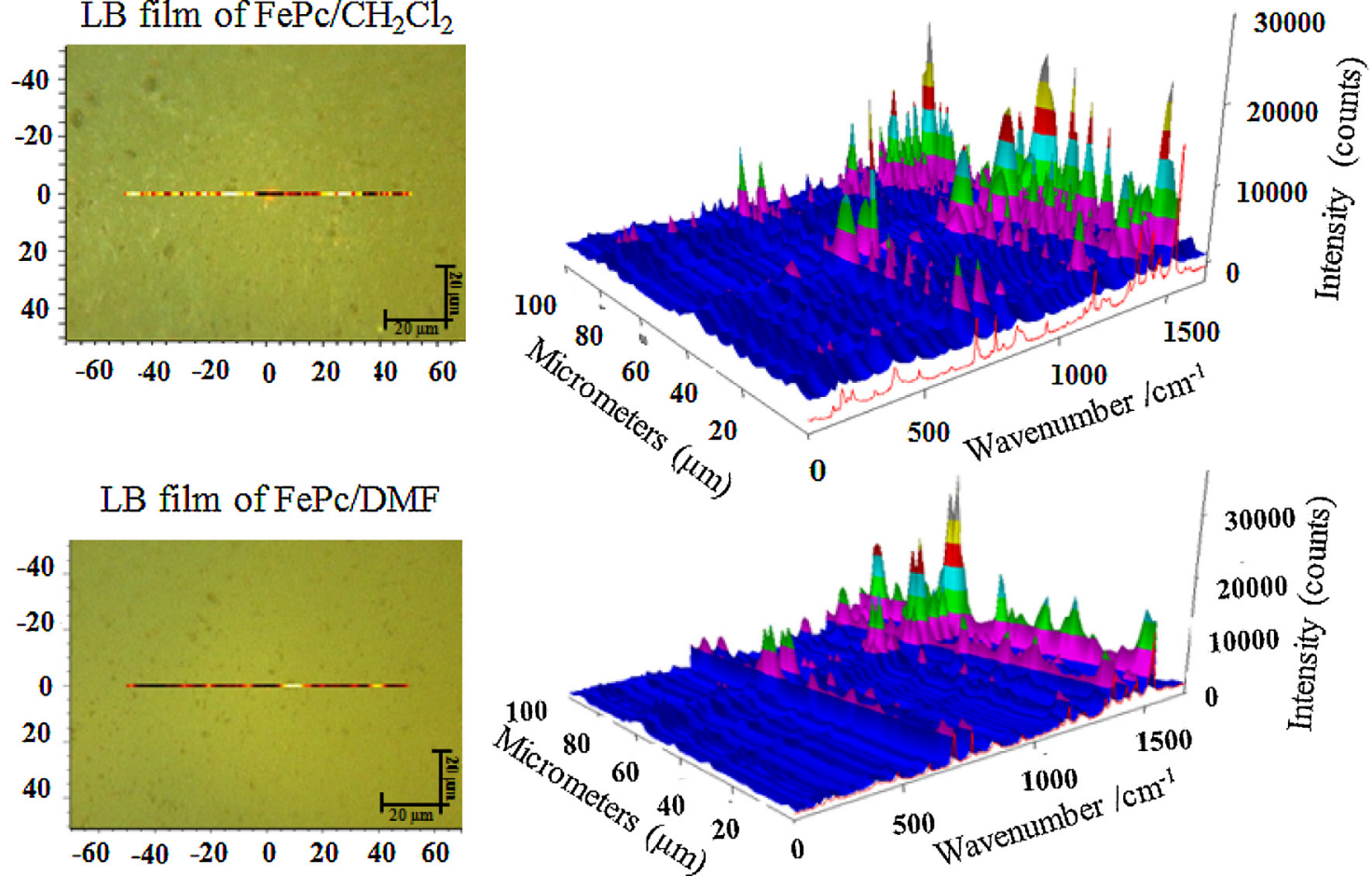

LB film of $\mathrm{FePc} / \mathrm{DMF}_{\text {aged }}$
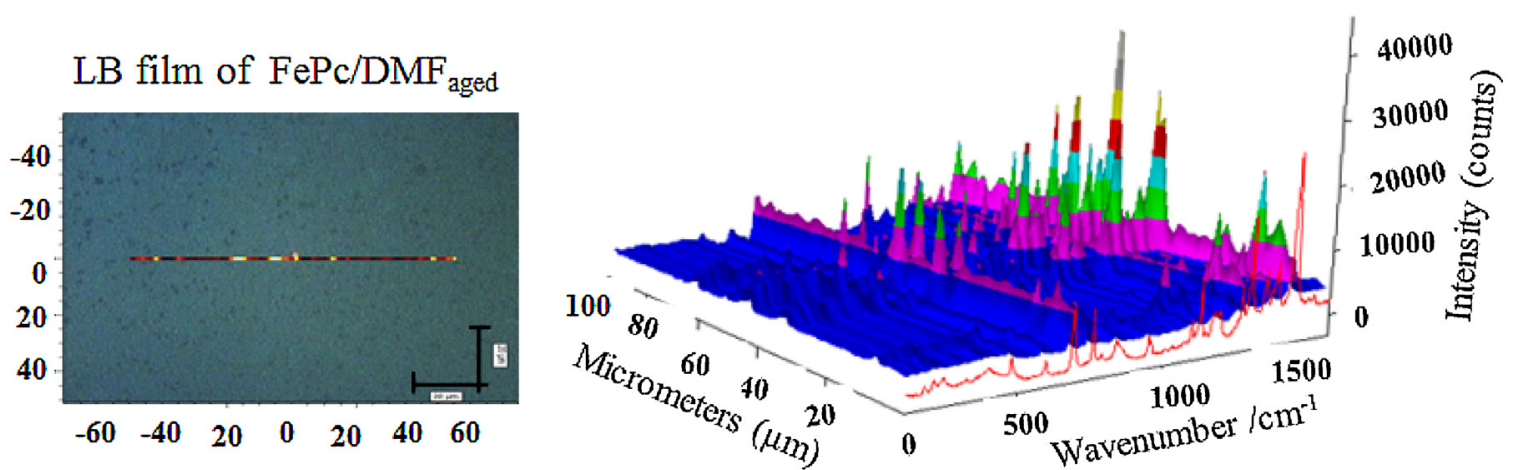

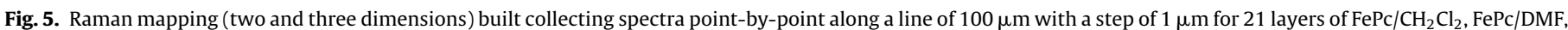

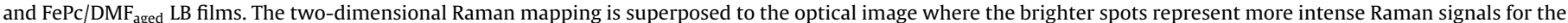
band at $1517 \mathrm{~cm}^{-1}$. The color of the optical image in $5 \mathrm{c}$ is not the real color of the FePc/DMF aged $\mathrm{LB}$ film.

LB film of $\mathrm{FePc} / \mathrm{CH}_{2} \mathrm{Cl}_{2}$

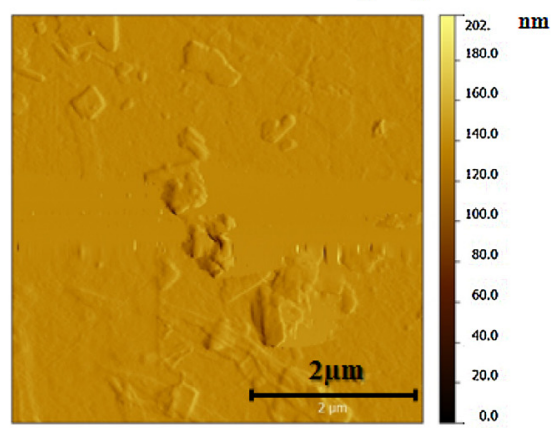

LB film of $\mathrm{FePc} / \mathrm{DMF}$

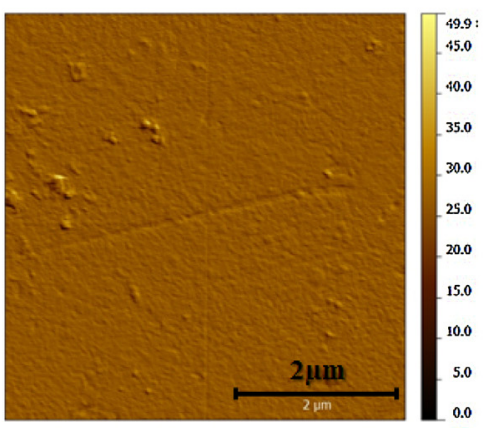

LB film of FePc/DMF ${ }_{\text {aged }}$

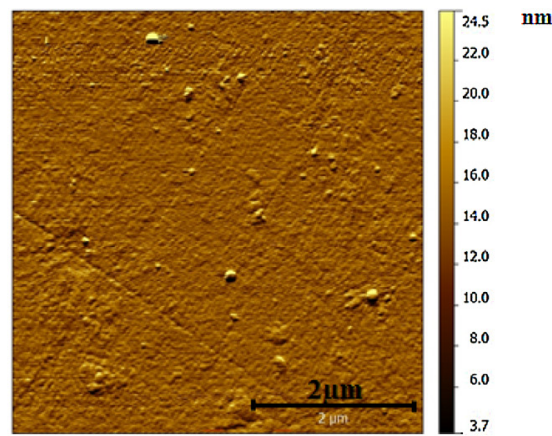

Fig. 6. AFM topographic images for 21 layers of $\mathrm{FePc} / \mathrm{CH}_{2} \mathrm{Cl}_{2}, \mathrm{FePc} / \mathrm{DMF}$, and FePc/DMF aged $\mathrm{LB}$ films deposited onto quartz plates, whose RMS is 0.89 nm.

Complementary, FTIR spectroscopy was carried out for 21 layers of $\mathrm{FePc} / \mathrm{CH}_{2} \mathrm{Cl}_{2} \mathrm{FePc} / \mathrm{DMF}$, FePc/DMF aged LB films (transmission mode) and 21 layers of FePc/DMF LB film (reflection mode), shown in Fig. 8. The bands at $1331 \mathrm{~cm}^{-1}$ (pyrrole stretching, C-N stretching, and in-plane $\mathrm{C}-\mathrm{H}$ bending) and $1338 \mathrm{~cm}^{-1}(\mathrm{C}-\mathrm{N}$ stretching), both related to the FePc ring vibration [42-44], had inverted their relative intensities. Other minor changes are observed for the band at $751 \mathrm{~cm}^{-1}$ (benzene deformation, isoindole deformation $[43,44]$ ), which had decreased its relative intensity for the FePc/DMF $\mathrm{Dged}_{\text {ab }}$ 


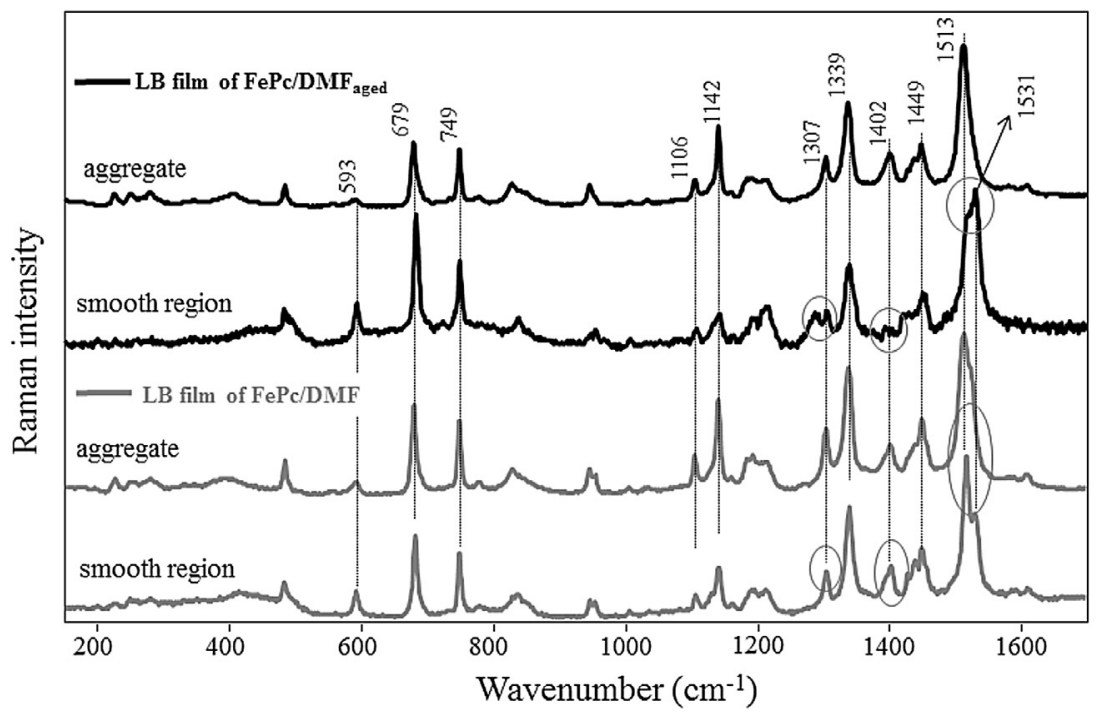

Fig. 7. Raman spectra of FePc/DMF and FePc/DMF ${ }_{\text {aged }}$ collected for both aggregates and smooth regions of the LB films.

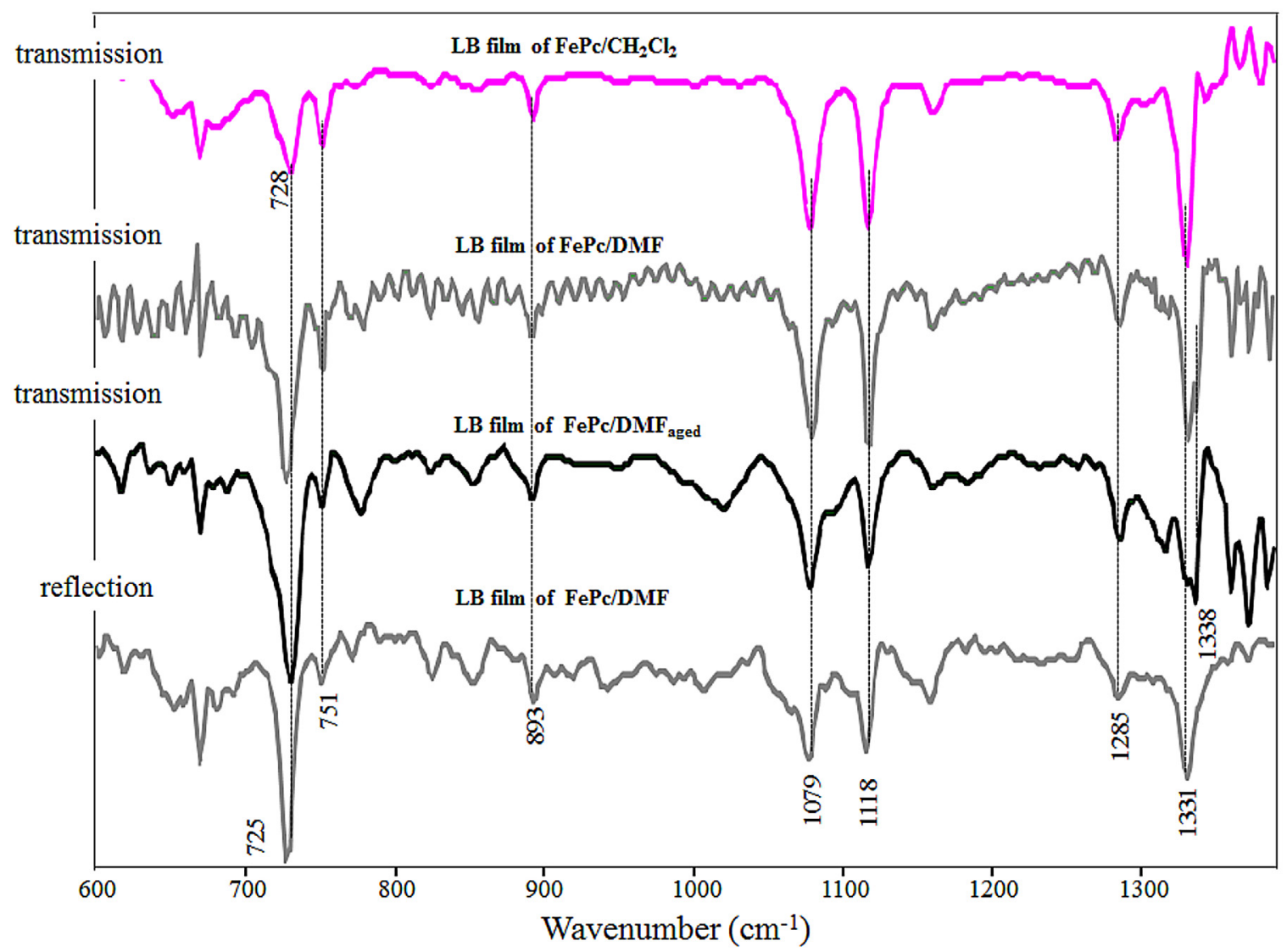

Fig. 8. FTIR spectra (transmission mode) for 21 layers of $\mathrm{FePc} / \mathrm{CH}_{2} \mathrm{Cl}_{2}$, FePc/DMF, and FePc/DMF aged LB films. Reflection mode for 21 layers of FePc/DMF LB Film.

film. These changes corroborate the results obtained from Raman spectroscopy (Fig. 7).

\subsubsection{Molecular organization}

analyses of the molecular organization were performed by FTIR (transmission and reflection modes - Fig. 8) for 21 layers of $\mathrm{FePc} / \mathrm{DMF}, \mathrm{FePc} / \mathrm{DMF}_{\text {aged }}$, and $\mathrm{FePc} / \mathrm{CH}_{2} \mathrm{Cl}_{2}$ LB films (Fig. 8). The spectral profile of the FePc/DMF LB film (freshly prepared) is pretty similar for both transmission and reflection modes (Fig. 8). Besides, both FTIR spectra are also similar to the FePc powder spectrum (transmission mode) shown in the work of Volpati et al. [1]. Because the powder spectrum is a reference to the random molecular organization, one can conclude the FePc molecules are isotropically organized in the FePc/DMF LB film. Considering the similarity of the FTIR spectra (transmission mode) in Fig. 8 for both FePc/DMF and $\mathrm{FePc} / \mathrm{DMF}_{\text {aged }}$, one can also conclude the aging process does not affect the isotropic molecular organization found for FePc/DMF LB film. On the other hand, the FTIR spectrum (transmission mode) 

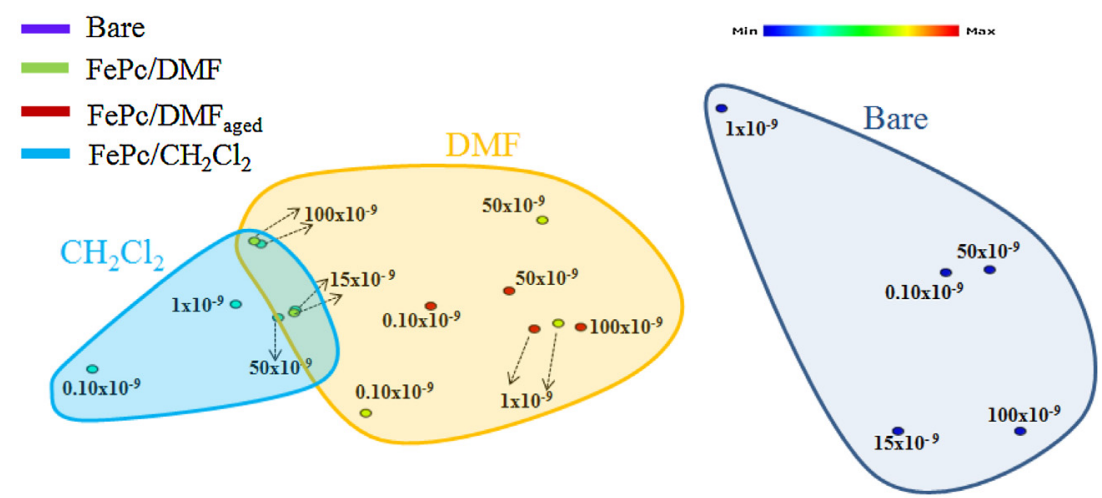

$15 \times 10^{-9} \bullet$

Fig. 9. IDMAP projection obtained using the real capacitance vs. frequency (Fig. S6) for the sensing array immersed into atrazine solutions. The sensing units are identified by the colors in the inset.

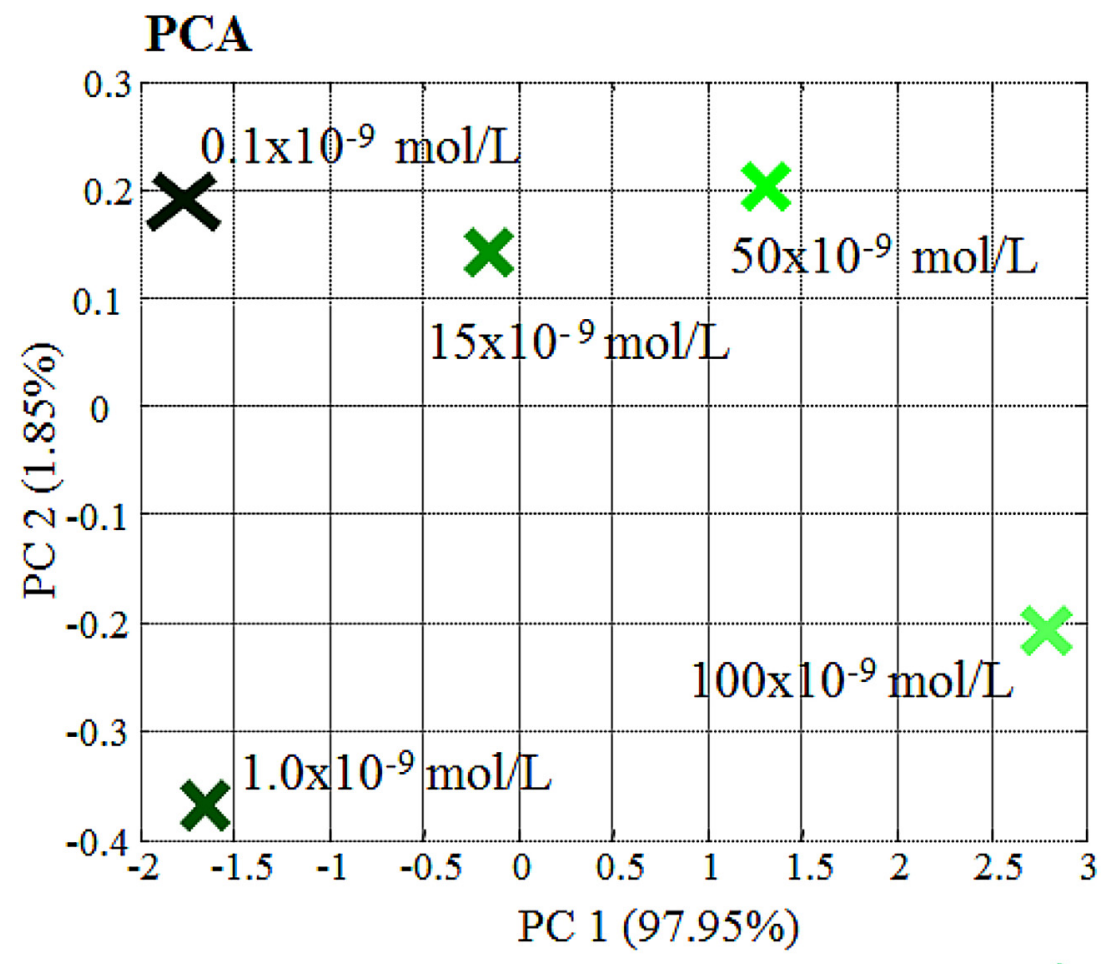

\section{Atrazine concentration}

Fig. 10. PCA obtained using the real capacitance vs. frequency at $501 \mathrm{~Hz}$ (Fig. S6) for the sensing array immersed into atrazine solutions.

for $\mathrm{FePc} / \mathrm{CH}_{2} \mathrm{Cl}_{2}$ (Fig. 8) is pretty similar to the $\mathrm{FePc} / \mathrm{CHCl}_{3} \mathrm{LB}$ film spectrum (transmission mode) obtained by Volpati et al. [1]. This similarity led the authors to conclude their LB films are with the FePc molecules organized with the macrocycle plane preferentially tilted between 0 and $45^{\circ}$ in relation to the substrate surface. Therefore, we can also conclude the FePc molecules forming $\mathrm{FePc} / \mathrm{CH}_{2} \mathrm{Cl}_{2}$ LB film are organized in the same way, i.e., macrocycle plane preferentially tilted between 0 and $45^{\circ}$ in relation to the substrate surface.

\subsection{Sensing of atrazine herbicide}

The performance of the FePc LB films as transducers in sensing applications was evaluated by immersing them into aqueous solutions containing atrazine at different molar concentrations. The sensor array was composed by one bare Pt IDE, and three Pt IDEs coated with 5 layers of FePc/DMF, FePc/DMF ${ }_{\text {aged }}$, and $\mathrm{FePc} / \mathrm{CH}_{2} \mathrm{Cl}_{2}$ LB films. This array allows direct comparison among the sensing units regarding the effect of the film supramolecular structures, achieved by the different solvents, on the impedance response. The real capacitance vs. frequency curves collected for the sensing units immersed into $0.1 \times 10^{-9}, 1.0 \times 10^{-9}, 15 \times 10^{-9}, 50 \times 10^{-9}$, and $100 \times 10^{-9} \mathrm{~mol} / \mathrm{L}$ atrazine solutions are shown in Fig. S6.

A visual inspection of Fig. S6 does not allow one to distinguish the samples with different atrazine concentrations. The distinction ability is demonstrated by treating the capacitance data in Fig. S6 using the IDMAP [39] multidimensional projection technique, whose results are given in Fig. 9. The electrical responses from each sensing unit and for each solution are plotted individually. Circle colors identify the sensing unit, while the atrazine concentration is shown next to each circle in the plot. Because the closer the cir- 
cles the more similar the electrical responses, it is observed the following: (i) the bare Pt electrode is positioned apart from the sensing units, revealing the film effect on the electrical response of the IDEs, in spite of being ultrathin; (ii) the sensing units composed of FePc/DMF and FePc/DMF ${ }_{\text {aged }}$ LB films are more similar to each other than the $\mathrm{FePc} / \mathrm{CH}_{2} \mathrm{Cl}_{2}$ LB film, highlighting the effect of the supramolecular structure of the films in this sort of sensor; (iii) the sensing units can distinguish atrazine solutions even down to $10^{-10} \mathrm{~mol} / \mathrm{L}$, sufficient to monitor the quality of drinking water even according to the most stringent international regulations [45]. Evidently, the sensing array was probed as proof-of-principle in ultrapure water. A real system would require measurements that are out of the scope of this article.

Fig. 9 is consistent with the PCA analysis shown in Fig. 10, revealing the sensing units achieve their purpose, i.e. distinguish atrazine concentrations. This result was obtained with a correlation of ca. 98\% to PC1 for atrazine concentration, which shows the combined sensing units can perform the role that is expected of a sensor: distinguish (classify) the different concentrations of certain analyte (atrazine).

\section{Conclusion}

A systematic study was performed to investigate the influence of different solvents $\left(\mathrm{CHCl}_{3}, \mathrm{CH}_{2} \mathrm{Cl}_{2}, \mathrm{DMF}\right.$, and $\left.\mathrm{THF}\right)$ on the supramolecular architecture of FePc Langmuir and LangmuirBlodgett (LB) films. Besides the FePc molecular organization in LB films, different morphological and optical properties are also dependent on the solvent. Coordination bonds between N-Fe lead to stronger DMF-FePc interaction, providing less FePc aggregation in solutions (for a certain concentration), and Langmuir and LB films with more homogeneous (surface morphology) when compared to the films built up from FePc solutions in $\mathrm{CHCl}_{3}, \mathrm{CH}_{2} \mathrm{Cl}_{2}$, and THF. The DMF-FePc interaction also leads to LB films with the FePc molecules isotropically organized, while for $\mathrm{CH}_{2} \mathrm{Cl}_{2}$ the FePc molecules are with the macrocycle preferentially tilted between 0 and $45^{\circ}$. Nevertheless, the DMF-FePc interaction has shown to be time-dependent, increasing the FePc aggregation with time. Such differences in the supramolecular architecture are also reflected in the electric response of FePc LB films deposited onto Pt interdigitated electrodes when immersed into atrazine aqueous solutions. The role played by the different FePc supramolecular architectures could be accessed by information visualization methods, which also revealed a high sensitivity of the sensor array to detect atrazine solutions down to $10^{-10} \mathrm{~mol} / \mathrm{L}$.

\section{Acknowledgments}

This work was supported by FAPESP, CNPq and CAPES.

\section{Appendix A. Supplementary data}

Supplementary data associated with this article can be found, in the online version, at http://dx.doi.org/10.1016/j.apsusc.2017.04. $155 \% 20001$

\section{References}

[1] D. Volpati, P. Alessio, A.A. Zanfolim, F.C. Storti, A.E. Job, M. Ferreira, A. Riul, O.N. Oliveira, C.J.L. Constantino, Exploiting distinct molecular architectures of ultrathin films made with iron phthalocyanine for sensing, J. Phys. Chem. B 112 (2008) 15275-15282, http://dx.doi.org/10.1021/jp804159h.

[2] P. Alessio, F.J. Pavinatto, O.N. Oliveira Jr, J.A. De Saja Saez, C.J.L. Constantino, M.L. Rodríguez-Méndez, Detection of catechol using mixed Langmuir-Blodgett films of a phospholipid and phthalocyanines as voltammetric sensors, Analyst 135 (2010) 2591, http://dx.doi.org/10.1039/ c0an00159g.
[3] M. Xu, F. Huo, C. Yin, A supramolecular sensor system to detect amino acids with different carboxyl groups, Sens. Actuators B Chem. 240 (2017) 1245-1250, http://dx.doi.org/10.1016/j.snb.2016.09.105.

[4] D. Gontero, M. Lessard-Viger, D. Brouard, A.G. Bracamonte, D. Boudreau, A.V. Veglia, Smart multifunctional nanoparticles design as sensors and drug delivery systems based on supramolecular chemistry, Microchem. J. 130 (2017) 316-328, http://dx.doi.org/10.1016/j.microc.2016.10.007.

[5] A. Bertolani, L. Pirrie, L. Stefan, N. Houbenov, J.S. Haataja, L. Catalano, G. Terraneo, G. Giancane, L. Valli, R. Milani, O. Ikkala, G. Resnati, P. Metrangolo, Supramolecular amplification of amyloid self-assembly by iodination, Nat. Commun. 6 (2015) 7574, http://dx.doi.org/10.1038/ncomms8574.

[6] K. Ariga, M. Li, G.J. Richards, J.P. Hill, Nanoarchitectonics a conceptual paradigm for design and synthesis of dimension-controlled functional nanomaterials, J. Nanosci. Nanotechnol. 11 (2011) 1-13, http://dx.doi.org/10. 1166/jnn.2011.3839.

[7] P.H.B. Aoki, P. Alessio, L.N. Furini, C.J.L. Constantino, Neves T.T.A.T, F.V. Paulovich, M.C.F. de Oliveira, O.N. Oliveira, Molecularly designed layer-by-Layer (LbL) films to detect catechol using information visualization methods, Langmuir 29 (2013) 7542-7550, http://dx.doi.org/10.1021/ la304544d.

[8] P. Aléssio, C.J.L. Constantino, A.E. Job, R. Aroca, E.R.P. González, Molecular architecture of thin films fabricated via physical vapor deposition and containing a poly(azo)urethane, J. Nanosci. Nanotechnol. 10 (2010) 3012-3021, http://dx.doi.org/10.1166/jnn.2010.1923.

[9] I. Langmuir, The constitution and fundamental properties of solids and liquids II. Liquids, J. Am. Chem. Soc. 39 (1917) 1848-1906, http://dx.doi.org/10.1021/ ja02254a006.

[10] K.B. Blodgett, Films built by depositing successive monomolecular layers on a solid surface, J. Am. Chem. Soc. 57 (1935) 1007-1022, http://dx.doi.org/10. 1021/ja01309a011.

[11] R. Gareth, Langmuir-Blodgett Films, 1 ed., 1990.

[12] M.C. Petty, Langmuir-Blodgett Films -An Introduction, 1996.

[13] A. Kam, R. Aroca, J. Duff, C.P. Tripp, Evolution of the molecular organization in bis(n - propylimido)perylene films under thermal annealing, Chem. Mater. 10 (1998) 172-176, http://dx.doi.org/10.1021/cm970299t.

[14] T.-Y. Chiang, M.-C. Huang, C.-H. Tsai, The effects of solvent on the electrochromic properties of poly(3, 4-ethylenedioxythiophene), RSC Adv. 4 (2014) 21201, http://dx.doi.org/10.1039/c4ra01618a.

[15] S. Ming, Z. Feng, D. Mo, Z. Wang, K. Lin, B. Lu, J. Xu, Solvent effects on electrosynthesis, morphological and electrochromic properties of a nitrogen analog of PEDOT, Phys. Chem. Chem. Phys. 18 (2016) 5129-5138, http://dx. doi.org/10.1039/C5CP04721H.

[16] M. Xiao, X. Zhang, Z.J. Bryan, J. Jasensky, A.J. McNeil, Z. Chen, Effect of solvent on surface ordering of poly(3-hexylthiophene) thin films, Langmuir 31 (2015) 5050-5056, http://dx.doi.org/10.1021/la5048722.

[17] A.M. Kolker, V. Erokhin, N.Y. Borovkov, Solvent-assisted interfacial assembly of copper tetra-(tert - butyl)-phthalocyanine into ultrathin films, J. Phys. Chem. C 120 (2016) 12706-12712, http://dx.doi.org/10.1021/acs.jpcc. $6 \mathrm{~b} 04180$.

[18] R. Rella, A. Rizzo, A. Licciulli, P. Siciliano, L. Troisi, L. Valli, Tests in controlled atmosphere on new optical gas sensing layers based on TiO2/metal-phthalocyanines hybrid system, Mater. Sci. Eng. C 22 (2002) 439-443, http://dx.doi.org/10.1016/S0928-4931(02)00193-5.

[19] J. Spadavecchia, G. Ciccarella, L. Valli, R. Rella, A novel multisensing optical approach based on a single phthalocyanine thin films to monitoring volatile organic compounds, Sens. Actuators B Chem. 113 (2006) 516-525, http://dx. doi.org/10.1016/j.snb.2005.03.110.

[20] V. Chidambara, C.M. Joseph, Electrical bistability studies on vacuum evaporated copper phthalocyanine (CuPc)/fullerene (C60) bilayers, Dyes Pigments 117 (2015) 24-27, http://dx.doi.org/10.1016/j.dyepig.2015.01.024.

[21] H. Wang, L. Zhao, X. Liu, J. Xu, W. Hou, J. Wang, E. He, R. Zhang, H. Zhang, Novel hydrogen bonding composite based on copper phthalocyanine/perylene diimide derivatives p-n heterojunction with improved photocatalytic activity, Dyes Pigments 137 (2017) 322-328, http:// dx.doi.org/10.1016/j.dyepig.2016.11.014.

[22] D. Dini, Phthalocyanines as materials for advanced technologies: some examples, J. Porphyr. Phthalocyanines 8 (2004) 915-933.

[23] R. Rella, A. Serra, P. Siciliano, A. Tepore, L. Valli, A. Zocco, Effects of NO2 oxidizing gas on a novel phthalocyanine Langmuir-Blodgett thin film, Thin Solid Films 286 (1996) 256-258, http://dx.doi.org/10.1016/S00406090(95)08491-6.

[24] R. Rella, A. Serra, P. Siciliano, A. Tepore, L. Valli, A. Zocco, NO2 gas detection by Langmuir-Blodgett films of copper phthalocyanine multilayer structures, Supramol. Sci. 4 (1997) 461-464, http://dx.doi.org/10.1016/S09685677(97)00029-1.

[25] L. Edwards, M. Gouterman, Porphyrins, J. Mol. Spectrosc. 33 (1970) 292-310, http://dx.doi.org/10.1016/0022-2852(70)90040-8.

[26] A.W. Snow, N.L. Jarvis, Molecular association and monolayer formation of soluble phthalocyanine compounds, J. Am. Chem. Soc. 106 (1984) 4706-4711, http://dx.doi.org/10.1021/ja00329a012.

[27] L. Guo, G. Ma, Y. Liu, J. Mi, S. Qian, L. Qiu, Optical and non-linear optical properties of vanadium oxide phthalocyanine films, Appl. Phys. B 74 (2002) 253-257, http://dx.doi.org/10.1007/s003400200801.

[28] G. Maggioni, M. Manera, J. Spadavecchia, M. Tonezzer, S. Carturan, A. Quaranta, C. Dejulianfernandez, R. Rella, P. Siciliano, G. Dellamea, Optical response of plasma-deposited zinc phthalocyanine films to volatile organic 
compounds, Sens. Actuators B Chem. 127 (2007) 150-156, http://dx.doi.org/ 10.1016/j.snb.2007.07.050.

[29] V. Zucolotto, M. Ferreira, M.R. Cordeiro, C.J.L. Constantino, D.T. Balogh, A.R. Zanatta, W.C. Moreira, O.N. Oliveira, Unusual interactions binding iron tetrasulfonated phthalocyanine and poly(allylamine hydrochloride) in layer-by-Layer films, J. Phys. Chem. B 107 (2003) 3733-3737, http://dx.doi. org/10.1021/jp027573d.

[30] P.M. Barbosa, A.M. Dias, V.R.L. Ferreira, Mg-Al hydrotalcite-like compounds containing iron-phthalocyanine complex: effect of aluminum substitution on the complex adsorption features and catalytic activity, Appl. Clay Sci. 28 (2005) 147-158, http://dx.doi.org/10.1016/j.clay.2004.02.002.

[31] V. Rives, M. Angeles Ulibarri, Layered double hydroxides (LDH) intercalated with metal coordination compounds and oxometalates, Coord. Chem. Rev. 181 (1999) 61-120, http://dx.doi.org/10.1016/S0010-8545(98)00216-1.

[32] W. Mulbry, The triazine hydrolase gene trzN from Nocardioides sp. strain C190: Cloning and construction of gene-specific primers, FEMS Microbiol. Lett. 206 (2002) 75-79, http://dx.doi.org/10.1016/S0378-1097(01)00517-1.

[33] S. Knauert, B. Escher, H. Singer, J. Hollender, K. Knauer, Mixture toxicity of three photosystem II inhibitors (atrazine, isoproturon, and diuron) toward photosynthesis of freshwater phytoplankton studied in outdoor mesocosms, Environ Sci. Technol. 42 (2008) 6424-6430, http://dx.doi.org/10.1021/ es072037q.

[34] L. Prade, R. Huber, B. Bieseler, Structures of herbicides in complex with their detoxifying enzyme glutathione S-transferase - explanations for the selectivity of the enzyme in plants, Struct. Fold. Des. 6 (1998) 1445-1452, http://dx.doi.org/10.1016/s0969-2126(98)00143-9.

[35] M. Kucka, K. Pogrmic-Majkic, S. Fa, S.S. Stojilkovic, R. Kovacevic, Atrazine acts as an endocrine disrupter by inhibiting cAMP-specific phosphodiesterase-4, Toxicol. Appl. Pharmacol. 265 (2012) 19-26, http://dx.doi.org/10.1016/j.taap. 2012.09.019.

[36] J.A. Rusiecki, A. De Roos, W.J. Lee, M. Dosemeci, J.H. Lubin, J.A. Hoppin, A. Blair, M.C.R. Alavanja, Cancer incidence among pesticide applicators exposed to atrazine in the agricultural health study, J. Natl. Cancer Inst. 96 (2004) 1375-1382.
[37] J.W. Simpkins, J.A. Swenberg, N. Weiss, D. Brusick, J.C. Eldridge, J.T. Stevens, R.J. Handa, R.C. Hovey, T.M. Plant, T.P. Pastoor, C.B. Breckenridge, Atrazine and breast cancer a framework assessment of the toxicological and epidemiological evidence, Toxicol. Sci. 123 (2011) 441-459, http://dx.doi.org/ $10.1093 /$ toxsci/kfr176.

[38] O.N. Oliveira Jr., F.J. Pavinatto, C.J.L. Constantino, F.V. Paulovich, M.C.F. de Oliveira, Information visualization to enhance sensitivity and selectivity in biosensing, Biointerphases 7 (2012), http://dx.doi.org/10.1007/s13758-0120053-7.

[39] F. Paulovich V, M.L. Moraes, R.M. Maki, M. Ferreira, O.N. Oliveira Jr., M.C.F. de Oliveira, Information visualization techniques for sensing and biosensing, Analyst 136 (2011) 1344-1350, http://dx.doi.org/10.1039/c0an00822b.

[40] C.C. Leznoff, A.B.P. Lever, Phthalocyanines: Properties and Applications, 1 ed., VCH-Publishers, New York, 1989

[41] P.J. Camp, A.C. Jones, R.K. Neely, N.M. Speirs, Aggregation of copper(II) tetrasulfonated phthalocyanine in aqueous salt solutions, J. Phys. Chem. A 106 (2002) 10725-10732, http://dx.doi.org/10.1021/jp026551o.

[42] P. Alessio, M.L. Rodríguez-Méndez, J.A. De Saja Saez, C.J.L. Constantino, Iron phthalocyanine in non-aqueous medium forming layer-by-layer films: growth mechanism, molecular architecture and applications, Phys. Chem. Chem. Phys 12 (2010) 3972, http://dx.doi.org/10.1039/b922242c.

[43] R. Aroca, A. Thedchanamoorthy, Vibrational studies of molecular organization in evaporated phthalocyanine thin solid films, Chem. Mater. 7 (1995) 69-74, http://dx.doi.org/10.1021/cm00049a012.

[44] Z. Liu, X. Zhang, Y. Zhang, J. Jiang, Theoretical investigation of the molecular, electronic structures and vibrational spectra of a series of first transition metal phthalocyanines, Spectrochim. Acta Part A Mol. Biomol. Spectrosc. 67 (2007) 1232-1246, http://dx.doi.org/10.1016/j.saa.2006.10.013.

[45] http://ec.europa.eu/food/plant/protection/evaluation/existactive/list. atrazine.pdf, (2015). 